has shown that the supposed differences between these two "families" are less clear cut than was supposed.

Although Harris has probably done more than any other worker to piece togother the various organs of bennettitaleans which are normally found detached, his taxonomic treatment of the genera is characteristically empirical. $\mathrm{He}$ avoids the implications of connexion even when this has been very adequately established. $\mathrm{He}$ suggests that "the best treatment at present is to continue to be cautious, to keep the different organs apart under different names, and where one feels sure that certain organs belong to a single plant, to say so, but without affecting the name". To some neobotanists, who might visualize one goal of palaeobotany as the reassembling of whole plants from the fossil pieces (with a concomitant reduction in the number of names), this may sound like a counsel of despair; but to most palaeobotanists it is a philosophy of realism. If applied to all palaeobotanical nomenclature, it would save us from some of the sterile convulsions of name changing to which this science is especially prone.

W. G. Chaloner

\section{PSYCHOTIC STATES}

\section{Psychopathology of the Psychoses}

By Thomas Freeman. Pp. 215. (Tavistock: London, 1969.) $45 s$.

Dr Freeman is a clinical psychiatrist who has been preoccupied with the phenomena of psychotic illness for several years. His method and his point of view will be familiar to readers of his two previous volumes, Chronic Schizophrenia (1958) and Studies on Psychosis (1965). In this book he brings together his clinical experience and his interest in theory to formulate a point of view: "Only the study of psychopathology, with its emphasis on the way in which patients experienco their thoughts, feelings, bodily sensations, and the world around them, can provide the material that will give a reliable foundation for clinical, physiological and biochemical investigations. The major contribution to this psychopathology comes from psychoanalysis".

After a proliminary discussion of the relevant theories advanced by Freud and Hughlings Jackson, the author outlines his method of categorizing and recording the clinical manifestations of psychotic states. Most of the remaining chapters are taken up with a discussion of his scheme in relation to various forms of psychosis, along with illustrative material. A final chapter is conecrned with some of the therapeutic implications of this approach.

The underlying outlook and concepts will not bo new to readers who are familiar with the literature on the subject. Nor will the unconvinced be persuaded that the author has in any way refuted Karl Jaspers's critique of psychoanalysis as a psychology of meaningful, but not explanatory, connexions. None the less, the book is clearly written and gives ample evidence of the care and patience required for the detailed clinical observations on which it is based. More space, however, might have been devoted profitably to the section entitled "Methodology of Clinical Observation" (pages 39-42) in which too little consideration is given to the reliability of the techniques used.

Michael Shepherd

\section{RETURN OF THE OSTRACIZED}

\section{Mental Imagery}

By Alan Richardson. Pp. xii + 180. (Routledge and Kegan Paul: London, August 1969.) 35s.

As Dr Alan Richardson points out in his foreword, the 1950 s and 1960s have seen a re-emergence of interest in mental imagery. He finds one good reason for its study in Robert Holt's 1964 paper "Imagery: the Return of the Ostracized", which shows how imagery can intrude on such activities as radar watching, long distance driving, polar exploration in snow cats and flying jet planes. Modern technological advances compel us to take account of potentially dangerous emergences of imagery and hallucination-like processes, and to return to scientific study of them.

There are also good theoretical reasons for taking account of imagery in an adequately scientific psychology of remembering, perceiving and thinking. Richardson deals with four principal classes: after-imagery, eidetic imagery, memory imagery and imagination imagery. He considers in some detail the curious imagery which some people experience in the hypnagogic or half-asleep state. Richardson's survey deals with early researches like those of Klüver into the stable, vivid and externally projected imagery called by Jaensch "eidetic". More rccent work cited includes Gordon's measurement of controllability of imagery, the factor-analytic studies of Barrett on imagory and of Singer and Antrobus on day-dreaming. Richardson describes his own experiments on mental practice, showing how performance in physical activities like high jumping can be improved by rehearsal in imagery. Stroboscopic experiments in augmenting imagery, EEG studies and the relationship of imagery to mnemonic systems are discussed. The treatment of imagery accompaniments of synaesthesia is largely confined to the work of the Russian Luria, in the detailed study over several decades of one individual subject to this.

The book is stronger in its reporting of the phenomena under study than in its survey of existing theory, or its own contributions to theory. Imagery is discussed largely in terms of two aspects: vividness (as measured by the Bett's scale) and susceptibility to manipulation (as measured by the Gordon test). Many things are mentioned but left undeveloped. Thus the book touchesomewhat lightly on such topics as dream imagery, inters sensory phenomena like synaesthesia, and behaviour therapy in its relation to the uses of imagery. In the treatment of hallucinogens, the incorrect spelling of mescaline (as "mescalin") is unfortunately perpetuated. It is pleasant to be able to welcome a book by a leading Australian psychologist which seeks "to bring together in one place a representative series of facts and hypotheses", after the undeserved neglect of these important and intrinsically interesting phenomena.

Peter McKellar

\section{Obituaries}

\section{Dr B. V. Rollin}

Bernard Vincent Rollin, who died on June 18, was one of a small band of physicists who started research in Oxford in the 1930s under Franz (later Professor Sir Francis) Simon. His first research problem was to design a combined hydrogen and helium liquefier, using the adiabatic expansion method for liquefying helium, which became the basis of the standard "Simple Simon" liquefier used in the Clarendon Laboratory at Oxford. With the help of this liquefier Rollin set out to measure the specific heat of liquid helium as a function of pressure; he discovered in the course of this work that the rate of evaporation from a vessel containing liquid helium increased 
dramatically when the temperature fell below the $\lambda$ point at $2 \cdot 19 \mathrm{~K}$.

A series of well planned experiments showed clearly that the effect was due to the presence of a liquid helium film on the inside of the pumping tube leading to the vessel, a result confirmed by the linear dependence of the evaporation rate on the tube diameter. Combined with an unexplained phenomenon observed in 1922 by Kamerlingh Onnes, when the levels of helium in two concentric dewars were seen to equalize, this led Rollin and Simon to suggest a thin mobile film transporting liquid from the cold lower end in the liquid to the warm upper end where it evaporated. It was in recognition of Rollin's contribution that Keesom in his classic monograph Helium coined the name "Rollin film". In 1936, Rollin, with Kurti, Lainé and Simon, carried out experiments at the Laboratoire du Grand Electro-Aimant in Bellevue (Paris) which led to the first liquefaction of helium in France, and the discovery of magnetic ordering in dilute paramagnetic salts at very low temperatures obtained by adiabatic demagnetization.

After two years (1937-39) at the University of California, Berkeley, as a Commonwealth Fund (now Harkness) Fellow, Rollin returned to the Clarendon Laboratory to join an Admiralty team working on receiving tubes and other techniques for centimetre waves. He suggested immediately the use of a secondary emission target to convert velocity modulation into amplitude modulation in a reflex klystron; though this gave a low starting current for oscillation, and tubes at both $10 \mathrm{~cm}$ and $3 \mathrm{~cm}$ wavelength were already in use in 1940 , it proved less stable, because of elcctrode contamination, than the system adopted later with a reflector at a negative voltage. In the later years of the war, Rollin carried out important development work on magnetrons for wavelengths in the $1 \mathrm{~cm}$ wavelength region.

In 1945 he started to extend the then novel technique of nuclear magnetic resonance to solids at low temperatures, using a simplified electronic system which became known as the "Rollin" circuit. In collaboration with J. Hatton, resonance was observed in liquid hydrogen, and in solid ortho-hydrogen the absorption line was found to split into a triplet. Nuclear magnetic resonances due to beryllium-9 and silicon-29 were detected at helium temperatures, the latter in part of a brown beer bottle in which spin-lattice relaxation was speeded by the presence of electronic paramagnetic impurities, the importance of which had become apparent during this work. After a lengthy effort to concentrate helium-3 from its natural abundance $\left(10^{-7}\right)$ to $10^{-2}$ by means of thermal diffusion, the nuclear resonance of helium-3 was sought but no signal could be detected. Instead, the small quantity of enriched helium was used to study the reaction ${ }^{3} \mathrm{He}+\mathrm{d} \rightarrow{ }^{4} \mathrm{He}+\mathrm{p}$, with the object of looking for excited states of the $\alpha$ particle.

Rollin then returned to an interest stimulated much earlier by Dr (now Professor) R. V. Jones, the development of a sensitive detector of infrared radiation, and devoted himself to the study of semi-conductors. Measurements of very low frequency "flicker" noise were made at low temperatures in germanium, but for the far infrared interest shifted to indium antimonide at liquid helium temperatures. Rollin proposed the use of the phenomenon of "hot electrons" generated in the semi-conductor by the absorption of radiation: the resultant change in their mobility was shown to provide a fast and sensitive detector of radiation at millimetre and sub-millimetre wavelengths.

Rollin was born on June 20, 1911, and went from Watford Grammar School to Wadham College, Oxford, as a scholar in 1930. He obtained first-class honours in physics in 1933, and took his D.Phil. in 1936. He becamo a university lecturer in Oxford in 1945, and a Fellow of Wolfson College in 1967. In 1964 he married Angela Margaret Moylan, who survives him.

\section{Correspondence}

\section{The EMBO Question Debated}

Sir,--Your account (Nature, 224, 406; 1969) of the recent meeting to discuss British participation in a European molecular biology laboratory did not consider all the factors affecting the desirability of setting up international laboratories. You point out that none of the equipment used in molecular biology is so expensive as to be beyond the reach of a laboratory financed by a university or research council. This distinguishes the EMBO proposal from, for example, CERN. A factor that was not mentioned is the location of the laboratory.

The argument that there is no case for a European molecular biology laboratory is valid. But there could be good reasons for other international laboratories that would use only ordinary equipment. For example, a large laboratory may be needed, for climatic or other reasons, in a region that is not industrialized. An institute in Antarctica is a case in point. More immediately useful would be an institute of food technology situated in the wet tropics and concerned exclusively with producing food (especially protein rich food) from local sources for local consumption. The work of such an institute would complement rather than overlap the work that is being done in industrialized countries; it would call on an abundant supply of scientific goodwill; and, if it is not financed and staffed internationally, it is difficult to see how it could be established because those who are now in most need of food have very little money.

\section{Yours faithfully,}

Department of Biochemistry,

N. W. PIRIE

Rothamsted Experimental Station,

Harpenden,

Hertfordshire.

\section{Private Army of Contributors}

SIR,-May I, in the interests of accuracy, make two comments on Dr Macleod's interesting article, "Private Army of Contributors", in the centenary issue of Nature $(224,445 ; 1969)$ ?

(1) The statement that I "was writing a biography of Lockyer in 1927-28" may strengthen a false impression that there exists such a biography, not elsewhere referred to in the supplement, bearing my name. The facts are these: there is only one published biography of Lockyer, variously referred to in the supplement, with the precise title "Life and Work of Sir Norman Lockyer" by T. Mary Lockyer and Winifred L. Lockyer with the assistance of Professor H. Dingle and contributions by Dr Charles E. St John; Professor Megh Nad Saha, FRS; Sir Napier Shaw, FRS; Professor H. N. Russell; the Rev J. Griffith; Sir Richard Gregory and Professor A. Fowler, FRS." Except for the "contributions" referred to, it was written by me, at the suggestion of Sir Richard Gregory, during the years 1922-28, from material selected by Lockyer's widow and daughter, and published by Macmillan in 1928.

(2) I have unearthed the notes I made at the time, and can now give an authentic version of Tait's characteristic verse which, as Dr Macleod says, he recorded as I (imperfectly) spoke it from memory. It is as follows:

Your printers have made but one curious blunder,

Correct it instanter, and then for the thunder!

We'll see in a jiffy if this Mr. S-

Has the ghost of a claim to be thought a good fencer.

To my vision his merits have still seemed to dwindle,

Since I found him allied with the great Dr. T-

While I have, for my part, grown cockier and cockier,

Since I found an ally in yourself, $\mathrm{Mr}$. L- 